women who work part time to provide an important part of the service. Is the College prepared to risk losing these women? The risk is real.

May I suggest either:

(a) Professional medical insurance is rated according to risk (psychiatrists are a low risk group); or (b) fees are related to time at work. (Those who work half time are surely half as likely to be sued as those who work full time).

It is normal practice amongst employers to pay their employees' professional insurance. Nurses' insurance is paid for them but not doctors'. Surely an iniquitous situation.

Finally the College could itself set an example of understanding for its women members and lower our current annual membership fee. Modelling is, after all, a potent method of altering behaviour.

Barrow Hospital

Dorcas Kingham

Barrow Gurney, Bristol

\section{Psychiatric services for the mentally handicapped}

DeAr SIRS

I welcome the article 'Psychiatric Services for Mentally Handicapped Adults and Young People' (Bulletin, November 1986, 10, 321-322). Although it is slightly delayed, nevertheless, I hope that it will clarify the confused planning that has been occurring at both District and Regional levels.

In the past, it was assumed that all mentally handicapped people (irrespective of their mental disturbances and behavioural disorders) could be resettled in small group homes supervised by community teams and that all mental handicap hospitals could be closed, thereby saving millions of pounds. In practice, however, this has proved impossible and not to be in the best interests of mentally handicapped people. Re-admission to hospital has occurred in many cases, to the bemusement of the planners, thereby indicating a fault in their policy and bringing about a great wastage of money.

This article recognises the need for base hospital facilities in each Health District where it will be possible to provide a 'specialised psychiatric service for mentally handicapped people' as and when necessary. It has been estimated that 0.25 beds per 1,000 populace would be required for each District.

There has been a dichotomy in planning between the DHSS and the Royal College of Psychiatrists which has resulted in tremendous confusion at Regional and District levels which has impeded resettlement programmes. I only hope that the DHSS will now accept the practicality of the Royal College of Psychiatrists' planning and issue an urgent directive to planners at Regional and District levels to modify their plans for psychiatric services for mentally handicapped people as suggested in the article.

Brockhall Hospital

U. J. DEY

Blackburn

\section{Prescription charges}

DeAr SIRS

We believe that the present system of prescription charges works to the disadvantage of many psychiatric patients and that pressure from professional and patient groups should be applied to effect immediate changes.

First, it is prudent clinical practice to provide potentially suicidal patients with short-term prescriptions, perhaps lasting only a few days. But each one must be paid for: there is a financial cost to thoughts of self-harm.

Second, there are many patients who require an additional drug to counteract the side-effects of their original prescription, e.g. anticholinergics with major tranquillisers. In effect they pay double because of the inadequacy of the first treatment. The same can be said of those who require two separate drugs to treat one disorder or those whose drug is rapidly switched because of lack of effect or unacceptable toxicity.

Third, there are some patients, such as those taking lithium, who require long-term maintenance therapy but who, unlike diabetics requiring insulin, must pay throughout their treatment.

The fact that a number of psychiatric patients are unable to find work and are consequently exempt from prescription payments should not obscure the unjust treatment of the others. Nor should our concentration on these specific failings imply support for the charge system in general: it is illogical in practice and inhumane in concept. Nevertheless there is no sign of its abolition. Clinicians must demand, therefore, that it operates fairly and push for necessary changes.

We suggest that the Royal College of Psychiatrists should request a revision of the payment system establishing (1) payment per course of treatment, irrespective of the number of drugs used and antidotes required or how frequently they must be dispensed because of, for example, a patient's suicidal urges; (2) exemption from payment of any patient on maintenance therapy, whether lithium, neuroleptics or antidepressants.

Institute of Psychiatry

LOUIS APPLEBY

London SES

The Maudsley Hospital

Michael FARRELL London SES

DeAr Sirs

\section{Closure of large mental hospitals}

The closing down of the large mental hospitals is resulting in the fragmentation of psychiatric service into small units on district general hospital sites, or stuck out on their own. While this has obvious advantages for patients and relatives not having to travel very far, it does have adverse implications for junior psychiatrists working in these units. They will be finding themselves working mainly with other disciplines with very little chance of day to day peer contact, with the eventual loss of the very important process of peer learning. 
While this is happening in many peripheral NHS units, teaching hospitals retain their status of having large numbers of trainees concentrated in one place. This will lead to the small units (even if they are part of a patched up rotation) finding it difficult to recruit career junior psychiatrists.

While the Short Report, as I understand it, is no longer the declared Government policy on medical manpower, I can see a situation where this will be happening by default, through the ever widening distinction in the organisation of teaching and non-teaching centres which will lead to the eventual drying up of applicants for peripheral junior jobs.

Fulbourn Hospital

R. T. ABED

Cambridge

\section{The established benefit of psychotherapy} DeAR SIRS

In a refreshing way McGrath \& Lowson (Journal. January 1987, 150, 65-71) moved beyond the well-known and ongoing arguments ${ }^{1}$ over psychotherapy by prioritising the economic appraisal of psychotherapy services. They concentrated on adult services, but Hill \& Cottrell (Bulletin. January 1987, 11, 19-21) offered a timely reminder of the importance of childhood and adolescent psychiatry which serves one quarter of our population. Neither paper, however, specifically mentioned child sexual abuse and it has great relevance for both.

A recent survey ${ }^{2}$ estimated that there are over 4.5 million adults in Great Britain who were sexually abused as children, and that a potential $1,117,000$ children will be sexually abused before they are 15 years of age. The therapeutic approach to sexual abuse has only recently been clarified in this country ${ }^{3}$ and though this is focused more on the family than the individual it is firmly based on psychotherapeutic principles. There is widespread agreement on the use of groups ${ }^{4}$ which pre-empts McGrath's question on efficiency of supply. The denial regarding sexual abuse has been pointed out ${ }^{5}$, but clearly such denial still persists at some level for many professionals. In recognising child sexual abuse and its treatment implications one cannot ignore one established benefit of psychotherapy.

JiM WATTERS

The Tavistock Clinic

London NW3

REFERENCES

'EysencK, H. J. (1987) Psychotherapy and placebo. British Journal of Psychiatry, 150, 266-267.

2BAKER, A. W. \& Duncan, S. P. (1985) Child sexual abuse: a study of prevalence in Great Britain. Child Abuse \& Neglect, 9, 457-467.

${ }^{3}$ Furniss, T., Bingley-Miller, L. \& Bentovim, A. (1984) Therapeutic approach to sexual abuse. Archives of Disease in Childhood, 59, 865-870.

4Steward, M. S., Farquhar, L. C., Dicharry, D. C., Glick, D. R. \& MARTIN, P. W. (1986) Group therapy: a treatment of choice for young victims of child abuse. International Journal of Group Psychotherapy, 36, 261-277.

${ }^{5}$ Lancet Editorial, (1986) Childhood depression and sexual abuse. Lancet, I, 196.

\section{Medical psychotherapist}

\section{DeAR SiRS}

Anyone can call themselves a psychotherapist (cf the personal column of any edition of the Hampstead and Highgate Express), despite attempts to define and restrict the use of the term by various bodies.

The recently created postgraduate degree course in psychotherapy at St George's Hospital Medical School is restricted to medical practitioners and prompts the suggestion that we consider a novel term, Medical Psychotherapist. I propose that this term be restricted to medically qualified practitioners who have satisfactorily managed at least two cases under approved supervision for at least one year each, the trainers to be approved by the Royal College of Psychiatrists and the training to be scrutinised and accredited by the Royal College of Psychiatrists on payment of a registration fee. Such an appelation would have several advantages:

(i) It would motivate the acquisition of the requisite experience by medical students, qualified physicians and psychiatrists in training to the benefit of patients whose psychopathology is often not recognised or little helped at present and it may well induce continuing interest in psychotherapy.

(ii) It would differentiate those so recognised from those who describe themselves as psychotherapists without any training or professional qualifications, and it would raise the standard of practice which, even in the case of the allegedly well trained, can result in consistently poor results. ${ }^{1}$

(iii) It would enable the College to monitor and flexibly promote alternative therapies, such as behavioural and cognitive psychotherapies, and to maintain a register of approved trainers whose status would be confirmed and enhanced.

(iv) It would increase the significance of the College and provide a source of revenue.

Friern Hospital

MALCOLM P. I. WelleR

London N1I

${ }^{1}$ STRUPP, H. H., HadLey, S. W. \& Gomez-SChWaARTZ, G. (1977) Psychotherapy for Better or Worse: The Problem of Negative Effects. New York: Jason Aronson.

\section{Responding to stigma}

DeAr SirS

One public act signifying a reduction in the stigma surrounding psychiatry in Britain would be for the Royal Household to appoint their own specialist in psychiatry as they have done with some other specialties.

Per Lassons vei 17

SimON R. WILKINSON 